\title{
Nephrotic Syndrome in Chronic Lymphocytic Leukaemia
}

\author{
J. R. E. DATHAN, M. F. HEYWORTH, A. G. MACIVER
}

British Medical fournal, 1974, 3, 655-657

\section{Summary}

Two patients with chronic lymphocytic leukaemia and the nephrotic syndrome are described in whom deposits were shown in renal glomerular basement membranes in a pattern suggesting immune-complex glomerulonephritis. This renal lesion has been described in one case of squamous carcinoma of the bronchus, in one case of Burkitt's lymphoma, and in three cases of Hodgkin's disease though not previously in chronic lymphocytic leukaemia. Immune-complex glomerulonephritis is, however, a recognized finding in mice infected with leukaemogenic viruses

\section{Introduction}

There are a number of reports of an association between malignant disease, especially of the reticulosis group, and the nephrotic syndrome. Hodgkin's disease has been most often described in this connexion, but there have been four documented cases in which chronic lymphocytic leukaemia was associated with the nephrotic syndrome (Scott, 1957; Leonard, 1957; Brodovsky et al., 1968). We present two further patients with this association, in each of whom deposits were shown in renal glomerular basement membranes in a distribution consistent with immune-complex glomerulonephritis.

\section{Case 1}

This patient was well until April 1972 when at the age of 63 he had a cerebrovascular accident which left him with a mild left hemiparesis. He was hypertensive (blood pressure 220/120 mm $\mathrm{Hg}$ ), and treatment with methyldopa was begun. One week before the cerebrovascular accident he had developed mild bilateral ankle oedema, which became more pronounced over the following months, and during this period he also notioed intermittent oedema of the left arm. He was admitted for investigation in September 1972 with gross oedema of both lower and upper limbs. Enlarged rubbery lymph nodes were found in the axillae and groins and the spleen was palable. His blood pressure was $220 / 100 \mathrm{~mm} \mathrm{Hg}$ and there was a mild left hemiparesis.

Investigation showed that he had chronic lymphocytic leukaemia with a total white cell count of $87,000 / \mathrm{mm}^{3}$ (91\% lymphocytes). A bone marrow aspirate and a right axillary lymph node biopsy showed histological features characteristic of chronic lymphocytic leukaemia. His total plasma protein was $4.3 \mathrm{~g} / 100 \mathrm{ml}$ with a low albumin concentration $(2.2 \mathrm{~g} / 100 \mathrm{ml})$, and the urine contained $5 \mathrm{~g}$ protein $/ 24 \mathrm{hr}$ (non-selective proteinuria). Serum cholesterol was $230 \mathrm{mg} / 100 \mathrm{ml}$, and plasma creatinine was raised at 2.34 $\mathrm{mg} / 100 \mathrm{ml}$. Plasma-protein electrophoresis showed marked reduction of $\gamma$-globulin, and individual immunoglobulin concentrations were all low (IgG $500 \mathrm{mg} / 100 \mathrm{ml}$; IgA $25 \mathrm{mg} / 100 \mathrm{ml}$; IgM $20 \mathrm{mg} / 100 \mathrm{ml}$ ). There was no evidence of myeloma. The serum complement (C3) level was normal $(125 \mathrm{mg} / 100 \mathrm{ml})$. No autoantibodies were detected and the result of the direct Coombs test was negative. Chest $x$-ray examination showed a left pleural

Department of Medicine, Royal South Hants Hospital, Southampton SO9 4PE

J. R. E. DATHAN, M.R.C.P., Consultant Physician

M. F. HEYWORTH, M.R.C.P., Registrar

Department of Morbid Anatomy and Experimental Pathology, University of Southampton, Southampton General Hospital, Southampton SO9 4XY

A. G. MacIVER, M.R.C.PATH., Senior Lecturer in Pathology

effusion, and an inferior venacavogram showed no evidence of renal vein thrombosis.

A percutaneous right renal biopsy was performed in October 1972. Light microscopy showed a prominent infiltrate of amorphous material in mesangium and basement membrane of all the glomeruli examined with reduction in capillary lumina (fig. 1). Hypertensive changes were seen in interlobular arteries and afferent arterioles, and focal infiltrates of small lymphocytes were present in the interstitium. Electron microscopy of the specimen showed marked thickening of the glomerular basement membranes owing to infiltration with amorphous material and accumulation of electrondense deposits. There was also endothelial, epithelial, and mesangial cell proliferation with fusion of epithelial cell foot processes (fig. 2). Immunofluorescent examination showed coarse granules and fluffy deposits of $\mathrm{C} 3$ on the basement membranes of all four glomeruli in the specimen (fig. 3). IgG and, to a lesser extent, IgA were present as coarse granules and fluffy deposits at the periphery of the glomerular tufts in two out of the four glomeruli. There was no evidence of amyloidosis on light or electron microscopy.

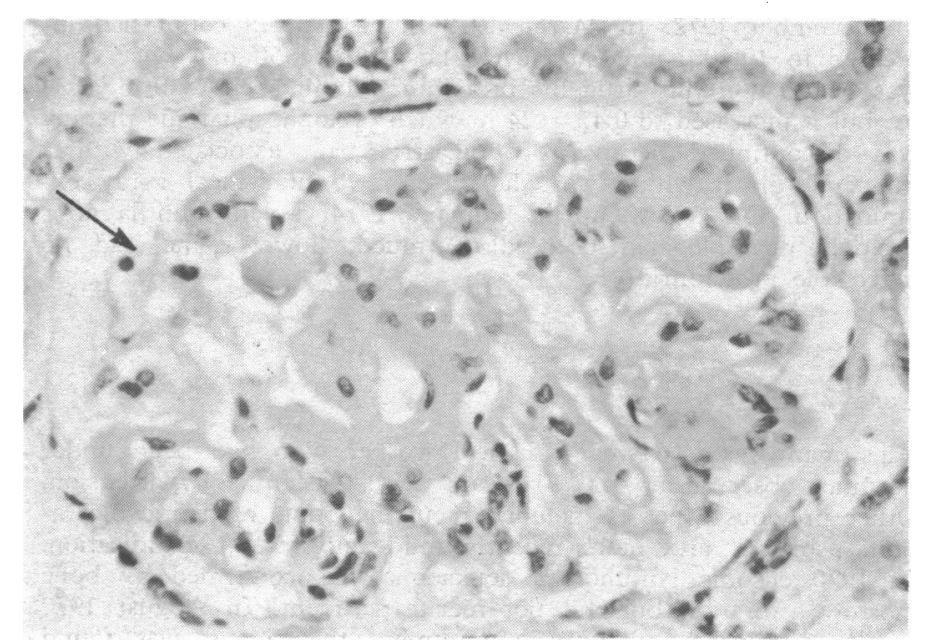

FIG. 1-Hypercellular glomerulus showing irregular accumulation of amorphous material apparently in glomerular basement membrane. Some capillaries are unaffected (arrowed). (H. and E. $\times 292$.)

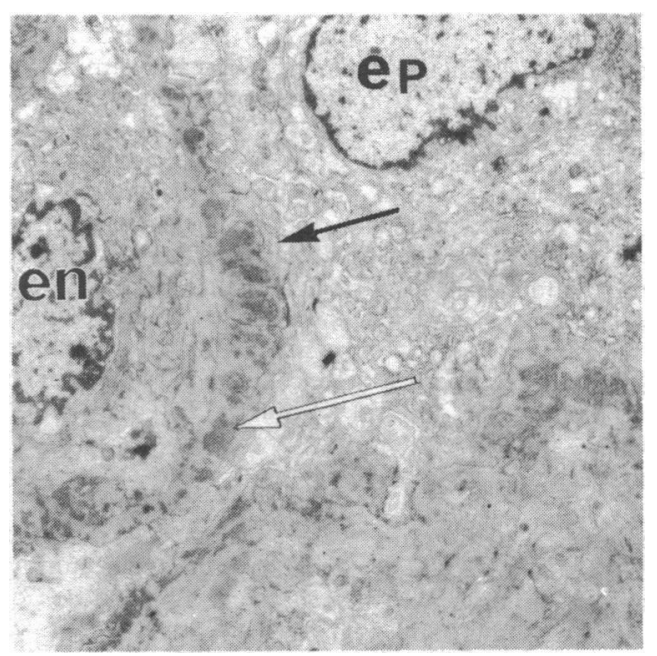

FIG. 2-Electron photomicrograph of glomerulus showing endothelial cell (en) and epithelial cell (ep) with marked increase in amount of cytoplasm and fusion of foot processes (black arrow). Electron-dense deposits are present in thickened glomerular capillary basement membrane (white arrow). $(\times 5,715$.) 


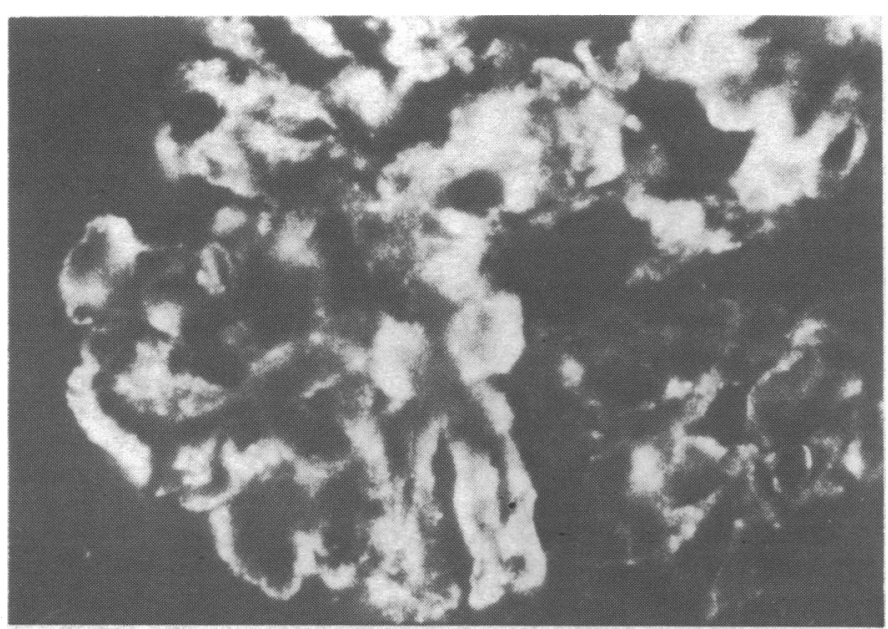

FIG. 3- Granular and fluffy deposits of $\mathrm{C} 3$ in glomerular basement membrane on immunofluorescent examination. $(\times 292$.)

Treatment was begun with chlorambucil, frusemide, and a high protein diet, and he was discharged from hospital. His oedema became less obvious and his white cell count decreased to 13,000/ $\mathrm{mm}^{3}$, but his proteinuria persisted and chlorambucil was stopped in December 1972. In March 1973 his white cell count had increased to $19,400 / \mathrm{mm}^{3}$, and cyclophosphamide $50 \mathrm{mg}$ twice daily was begun. On this drug his proteinuria diminished to $0.13 \mathrm{~g} / 24$ $\mathrm{hr}$, but it increased to $0.47 \mathrm{~g} / 24 \mathrm{hr}$ when cyclophosphamide therapy was discontinued because of epigastric pain associated with a duodenal ulcer, which was shown on a barium-meal $x$-ray examination. On follow up in January 1974, seven months after cyclophosphamide had been discontinued, however, he had no detectable proteinuria.

\section{Case 2}

This man was a 65-year-old steel worker who had been under hospital observation for 10 years with systemic hypertension. Other previous illnesses included recurring bouts of peptic uloeration, psoriasis, and more recently mild intermittent claudication. In 1970 chronic lymphocytic leukaemia was confirmed by bone marrow aspiration but did not merit treatment. In August 1972 during a routine follow-up appointment the patient was found to have developed the nephrotic syndrome with a daily urinary protein loss subsequently determined as between 6-8 g/24 $\mathrm{hr}$. His treatment at that time consisted of guanethidine, frusemide, and potassium supplements. Examination on admission to hospital showed gross dependent oedema, ascites, systemic hypertension of $170 / 110 \mathrm{~mm} \mathrm{Hg}$ a few small peripheral lymph nodes, and hepatosplenomegaly. The rest of the clinical examination showed nothing abnormal apart from occasional cellular casts in the urinary deposit.

Investigation confirmed the previous diagnosis of chronic lymphocytic leukaemia, with a total white cell count of $24,000 / \mathrm{mm}^{3}$ and a peripheral blood film showing "many smear cells and large lymphocytes containing nucleoli." Apart from his proteinuria the patient's renal function was normal and urine cultures were sterile. Estimations of the $\mathrm{C} 3$ and $\mathrm{C} 4$ components of complement as well as "total haemolytic assay" for complement found that they were all raised. No autoantibodies were detected in the serum. Serum proteins totalled $4.8 \mathrm{~g} / 100 \mathrm{ml}$ (albumin $1.9 \mathrm{~g} / 100 \mathrm{ml}$, globulin $2.9 \mathrm{~g} / 100 \mathrm{ml}$ ), and his proteinuria was non-selective. Light microscopy examination of a renal biopsy specimen showed focal proliferation of some glomenular tufts, while in other areas segments of the basement membrane were thickened. Immunofluorscent staining of the same biopsy specimen showed a "lumpy bumpy" distribution of deposits which contained IgG and C3. Staining reactions for $\operatorname{IgA}$, IgM, and $\operatorname{IgE}$ were negative.

Conservative treatment of his nephrotic syndrome with salt restriction and spironolactone was sucoessful in controlling both the ascites and the oedema. It was not thought necessary to treat his leukaemia with cytotoxic drugs and his renal function, as judged by measurements of blood urea and creatinine clearance, remained normal for eight months after his discharge from hospital. At this time he developed evidence of a deep venous thrombosis in the right leg, which responded satisfactorily to anticoagulation treatment.

\section{Discussion}

It is of interest that mice infected with oncogenic viruses (Moloney leukaemogenic virus, murine sarcoma virus, and wild-type Gross leukaemia virus) develop immune-complex glomerulonephritis in which viral antigens and antiviral immunoglobulins can be shown in the glomeruli by immunofluorescent techniques (Holmes and Burnet, 1963; Recher et al., 1966; Hirsch et al., 1969; Branca et al., 1971; Mellors et al., 1971).

In three previously described cases of Hodgkin's disease associated with the nephrotic syndrome renal biopsy showed evidence of deposition of complexes. In one of these electron microscopy showed electron-dense deposits on the epithelial aspect of glomerular capillary basement membranes, and immunofluorescence microscopy showed the presence of IgG and C3 in these deposits (Froom et al., 1972). One of the other cases was a child with Hodgkin's disease in whom deposits of IgG, IgM, C3, and C4 were present in the glomeruli, and a renal biopsy specimen from the third patient in this group showed glomerular deposits of fibrin, IgM, C3, and C4 (Hyman et al., 1973). A child with Burkitt's lymphoma and the nephrotic syndrome has been described in whom a renal biopsy showed glomerular deposits of IgG, IgM, C3, C4, and fibrin (Hyman et al., 1973), and a patient with nephrotic syndrome and squamous carcinoma of the bronchus has been reported in whom immane complex glomerulonephritis was present (Lewis et al., 1971; Loughridge and Lewis, 1971). In this latter case IgG and IgM eluted from glomeruli obtained at necropsy reacted specifically with the surface membranes of the bronchial tumour cells.

The cases reported here are the first recorded patients in whom the nephrotic syndrome associated with chronic lymphocytic leukaemia has been shown to be related to the presence of discrete glomerular basement deposits and a pattern of fluorescence suggesting that these deposits contain C3 and immunoglobulins. There was no direct evidence of immune-complex glomerulonephritis but the demonstration of C3 and immunoglobulins in a discrete distribution on the glomerular basement membrane is consistent with the presence of immune complexes. The kidneys in the two cases described by Scott (1957) were examined at necropsy; one patient had renal amyloid, and the kidneys in the other case contained a lymphocytic infiltrate with some hyaline change in the glomeruli. The patient described by Leonard (1957) was found to have real amyloid and "cystic disease" in one kidney at necropsy while the other kidney was absent. Brodovsky et al. (1968) described a patient with chronic lymphocytic leukaemia and the nephrotic syndrome in whom a renal biopsy showed diffuse thickening of the glomerular basement membrane with focal areas of glomerulosclerosis. Low circulating immunoglobulin levels were recorded in this patient. Treatment of this patient with chlorambucil led to shrinkage of enlarged lymph nodes, improvement in blood picture, and diminution of proteinuria. There was no significant change in the degree of proteinuria in our case 1 during chlorambucil therapy though the white cell count return virtually to normal on this treatment.

The mechanism of the development of possible immune complex glomerulonephritis in the patients reported here remains obscure. It is conceivable that the association between chronic lymphocytic leukaemia and this type of renal lesion might become increasingly recognized if more renal biopsy specimens from patients with chronic lymphocytic leukaemia and proteinuria were examined. 
We thank Dr. A. L. Turnbull, consultant physician at the London Hospital for permission to report the second case and Dr. David Fisher, Cardiff Royal Infirmary, for preparing the report of this case.

\section{References}

Branca, M., et al. (1971). Clinical and Experimental Immunology, 9, 853. Brodovsky, H. S., et al. (1968). Archives of Internal Medicine, 121, 71.
Froom, D. W., et al. (1972). Archives of Pathology, 94, 547.

Hirsch, M. S., Allison, A. C., and Harvey, J. J. (1969). Nature, 223, 739. Holmes, M. C., and Burnet, F. M. (1963). Annals of Internal Medicine, 59, 265.

Hyman, L. R., et al. (1973). Fournal of Pediatrics, 82, 207.

Leonard, B. J. (1957). Lancet, 1, 1356.

Lewis, M. G., Loughridge, L. W., and Phillips, T. M. (1971). Lancet, 2, 134.

Loughridge, L. W., and Lewis, M. G. (1971). Lancet, 1, 256.

Mellors, R. C., et al. (1971). Fournal of Experimental Medicine, 133, 113.

Recher, L., et al. (1966). National Cancer Institute Monographs, 22, 459.

Scott, R. Bodley (1957). Lancet, 1, 1162.

\title{
Renal Insensitivity to Frusemide Caused by Chronic Anticonvulsant Therapy
}

\author{
SUHAIL AHMAD
}

British Medical Fournal, 1974, 3, 657-659

\section{Summary}

The diuretic response to $20-\mathrm{mg}$ and $40-\mathrm{mg}$ oral doses of frusemide was significantly smaller in a group of epileptic patients on chronic anticonvulsant therapy than in a group of normal staff members. Furthermore, the peak response was considerably delayed in the epileptic patients. The difference in the volume of diuresis was maintained after intravenous injection of $20 \mathrm{mg}$ of frusemide. It is suggested that the sensitivity of the renal tubule to the diuretic action of frusemide is reduced by anticonvulsant therapy and that there may also be delayed absorption of the drug from the gastrointestinal tract.

\section{Introduction}

In chronic epileptics in a residential centre the incidence of dependent oedema seemed to be greater than would be expected in a normal population and the response to diuretic therapy was poor. To evaluate this impression a study was undertaken to compare the diuretic response produced by frusemide in a group of epileptic patients on chronic anticonvulsant therapy and a group of normal staff members.

\section{Subjects and Methods}

A group of 30 long-stay patients at the Chalfont Centre for Epilepsy was studied. Patients were aged $20-48$ years and were in good health other than their chronic epilepsy. None had oedema, heart failure, or renal disease. Blood urea, serum electrolytes, creatinine, creatinine clearance, and 24-hour urinary excretion of sodium and potassium were normal. The results of investigations are shown for 17 patients in table I. All were receiving phenytoin sodium in doses of $200-400 \mathrm{mg}$ daily and

Chalfont Centre for Epilepsy, Chalfont St. Peter, Buckinghamshire SL9 ORJ

SUHAIL AHMED, B.sC., M.B., Assistant Physician phenobarbitone 60-180 mg daily. In addition, three were receiving carbamazepine, two pheneturide, two ethosuximide, three diazepam, and one chlordiazepoxide.

The normal subjects were of a similar age range, in good health, and not receiving drug therapy of any kind and comprised nurses, technicians, and doctors whose informed consent was obtained. The investigation was approved by the hospital ethical committee.

The study was placebo controlled, double blind, and randomized. A period of $\mathbf{4 8}$ hours was allowed between treatments for fluid balance to be restored. No restrictions were placed on fluid intake during the study and the subjects were allowed normal breakfast at 07.15 hours. Treatments were administered at 08.00 hours after emptying the bladder, and urine collections were subsequently made at hourly intervals for six hours after oral frusemide (20 mg and $40 \mathrm{mg}$ ) and every 15 minutes for 105 minutes after intravenous administration of the drug $(20 \mathrm{mg})$. The diuretic response was complete by the end of these periods in all subjects. The volume of each urine collection was measured and the difference between the urine volumes in the patients and normal subjects analysed by Student's $t$ test.

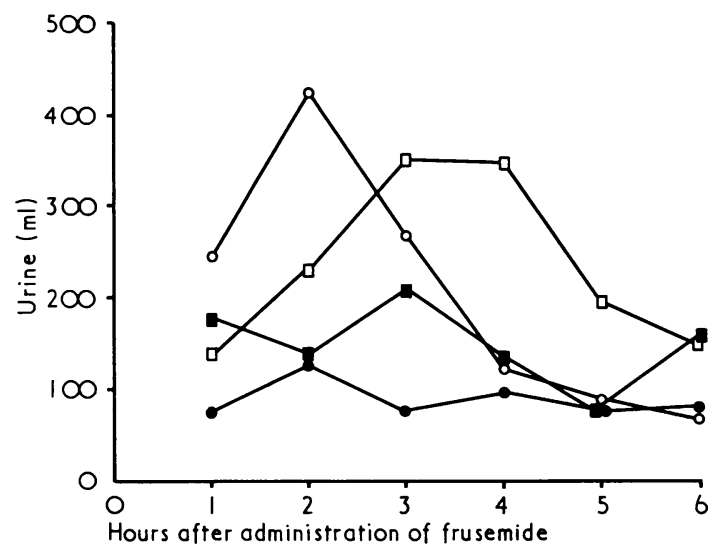

FIG. 1-Effect of oral frusemide $20 \mathrm{mg}$ and placebo in 14 Fig. 1 -Effect of oral frusemide $20 \mathrm{mg}$ and placebo in 14 patients on placebo. $O=$ Normal subjects on frusemide. $=$ Patients on placebo. $O=$ Normal subjects on placebo.
$=$ Normal

TABLE I-Blood and Urine Values in 17 Epileptic Patients

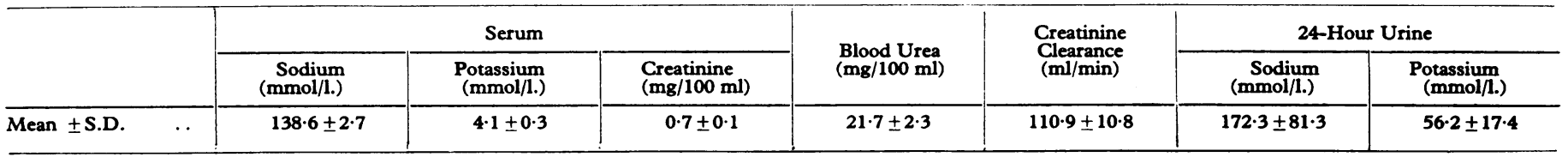

